\title{
Repeated Cocaine Augments Excitatory Amino Acid Transmission in the Nucleus Accumbens Only in Rats Having Developed Behavioral Sensitization
}

\author{
R. Christopher Pierce, Ken Bell, Patricia Duffy, and Peter W. Kalivas \\ Alcoholism and Drug Abuse Program, Washington State University, Pullman, Washington 99164-6520
}

Rats were pretreated with daily cocaine or saline injections for 1 week. The rats treated with daily cocaine were separated into two groups: a sensitized group of animals demonstrating $>20 \%$ increase in motor activity on the last injection compared with the first injection of daily cocaine, and a nonsensitized group showing $<20 \%$ elevation. At $2-3$ weeks after the last daily injection, four experiments were performed to assess changes in excitatory amino acid (EAA) transmission in the nucleus accumbens produced by repeated cocaine administration. (1) Rats were challenged with a microinjection of AMPA into the shell or core of the nucleus accumbens. The sensitized rats demonstrated greater motor activity than did the salinepretreated or nonsensitized animals after AMPA injection into either subnucleus. (2) It was shown that the behavioral distinction between sensitized, nonsensitized, and control rats in be- havioral responsiveness to AMPA was not mediated by differences in AMPA-induced dopamine release. (3) The extracellular content of glutamate was measured after a cocaine challenge given at $21 \mathrm{~d}$ of withdrawal. Cocaine elevated the levels of glutamate in the core of sensitized rats, but not of nonsensitized or control rats. (4) Microinjection of the non-NMDA antagonist 6-cyano-7-nitroquinoxaline-2,3-dione into the core abolished the augmented motor response to a cocaine challenge in sensitized rats, but was without effect on cocaine-induced motor activity in nonsensitized animals. These results indicate that repeated cocaine administration increases EAA transmission in the nucleus accumbens only in rats that develop behavioral sensitization to cocaine.

Key words: glutamate; cocaine; dopamine; nucleus accumbens; sensitization; microdialysis
Repeated administration of amphetamine-like psychostimulants causes a progressive and enduring augmentation in behavioral activation that is called behavioral sensitization (Segal and Schuckit, 1983; Robinson and Becker, 1986; Post and Weiss, 1988; Kalivas and Stewart, 1991). Both the behavioral hyperactivity and the reinforcing properties of these drugs arise, in part, from their capacity to increase dopamine neurotransmission (Kelly and Iversen, 1975; Clarke et al., 1988; Koob et al., 1993). As a result, research has focused on identifying alterations in dopamine transmission that may mediate behavioral sensitization (for review, see Robinson and Becker, 1986; Kalivas and Stewart, 1991; Nestler, 1992; White et al., 1995b). Because psychostimulant abuse in humans can manifest as paranoid psychosis (Angrist and Gershon, 1970; Post and Weiss, 1988; Sato, 1992) and because the mesoaccumbens dopamine projection has been postulated as a pathophysiological substrate for idiopathic psychosis (Goldstein and Deutch, 1992), many investigators have focused on a role for dopanine cell bodies in the ventral tegmental area and their axon terminals in the nucleus accumbens in the expression of behavioral sensitization to psychostimulants. To this end, a growing body of biochemical, electrophysiological, and behavioral evidence indicates that the mesoaccumbens dopamine system is involved in the expression of psychostimulant-induced behavioral

\footnotetext{
Received Aug. 31, 1995; revised Nov, 21, 1995; accepted Nov. 29, 1995.

This research was supported in part by the Washington State Alcohol and Drug Abuse Program and U.S. Public Health Service Grants MH-40817 and DA-03906, Research Career Development Award DA-00158 (P.W.K.), and National Research Service Awards DA-05589 (R.C.P.) and DA-05642 (K.B.). We thank Jenny Baylon for assistance in preparing this manuscript.

Correspondence should be addressed to Peter Kalivas at the above address. Copyright $(\mathcal{C} 1996$ Society for Neuroscience 0270-6474/96/161550-11\$05.00/0
}

sensitization (Robinson and Becker, 1986; Kalivas and Stewart, 1991; Nestler, 1992; White et al., 1995b).

Although the mesoaccumbens dopamine system appears to have a role in behavioral sensitization to psychostimulants, other neurotransmitter systems also may be important. Recent evidence suggests that alterations in excitatory amino acid (EAA) transmission contribute to the expression of behavioral sensitization. Behavioral sensitization to psychostimulants is inhibited by systemic administration of non-NMDA receptor antagonists (Karler et al., 1991, 1994) and by lesions of EAA projections from the amygdala, hippocampus, or prefrontal cortex to the nucleus accumbens (Yoshikawa et al., 1991; Pert et al., 1992; Dahlin et al., 1994).

Four experiments were conducted to evaluate the effect of repeated cocaine administration on EAA transmission in the nucleus accumbens. The subnuclei of the nucleus accumbens, the shell and core, were examined independently, because recent studies have identified functional distinctions between these two accumbal compartments (Deutch and Cameron, 1992; Maldonado-Irizarry and Kelley, 1994; Pulvirenti et al., 1994; Kalivas and Duffy, 1995; Pierce and Kalivas, 1995). All rats were pretreated for 1 week with daily cocaine or saline, and four experiments were conducted between 14 and $23 \mathrm{~d}$ after discontinuing daily administration. The following steps were taken. (1) Motor activity elicited by the microinjection of the non-NMDA agonist AMPA into the shell and core of the nucleus accumbens was measured. (2) AMPA-induced increase in extracellular dopamine was measured in the core and shell. (3) Cocaine-induced changes in extracellular levels of glutamate were measured in the shell and core. (4) The capacity of microinjection of the AMPA antagonist 6-cyano-7-nitroquinoxaline-2,3-dione (CNQX) into 
the core to alter the motor stimulant response to a cocaine challenge was determined.

\section{MATERIALS AND METHODS}

Animal housing and surgery. Male Sprague-Dawley rats (Simmonsen Laboratories, Gilroy, CA) were housed individually with food and water available ad libitum. A $12 \mathrm{hr}$ light/dark cycle was used, with the lights on at 6:30 A.M. All cocaine injections, behavioral testing, and microdialysis were performed during the light cycle.

Before surgery, rats weighing 250-350 gm were anesthetized with Equithesin $(3.0 \mathrm{ml} / \mathrm{kg})$ and mounted in a stereotaxic apparatus. For dialysis and microinjection experiments, cannulae (12 mm, 20-gauge stainless steel for dialysis; $14 \mathrm{~mm}$, 26-gauge for microinjection) were implanted bilaterally 3 or $1 \mathrm{~mm}$, respectively, dorsal to the nucleus accumbens shell or core $(9.0 \mathrm{~mm}$ anteroposterior; 0.8 or $2.0 \mathrm{~mm}$ mediolateral, respectively; $0.0 \mathrm{~mm}$ dorsoventral; relative to the interaural line) (Pellegrino et al., 1979) and cemented in place by affixing dental acrylic to three stainless steel screws that were tapped into the skull.

Repeated cocaine or saline treatment. In both behavior and dialysis experiments, all subjects were assigned to either the cocaine or the saline group after at least $7 \mathrm{~d}$ of postoperative recovery. The day before the start of the experiment, all animals were habituated to the photocell boxes (Omnitech Electronics, Columbus, $\mathrm{OH}$ ) for $3 \mathrm{hr}$. On the first treatment day, all animals were habituated to the photocell boxes for 1 hr. After habituation, animals received either cocaine $(15 \mathrm{mg} / \mathrm{kg}$, i.p.; donated by the National Institute of Drug Abuse, Bethesda, MD) or saline (1.0 $\mathrm{ml} / \mathrm{kg}$, i.p.), and subsequent behavior was monitored for $2 \mathrm{hr}$. On days $2-6$, rats received daily injections of cocaine $(30 \mathrm{mg} / \mathrm{kg}, \mathrm{i} . \mathrm{p}$.) or saline in the home cage. On day 7 , all animals were habituated again to the photocell boxes for $1 \mathrm{hr}$, followed by the administration of $15 \mathrm{mg} / \mathrm{kg}$, i.p., cocaine or saline, and behavior was monitored for $120 \mathrm{~min}$ after injection. This cocaine treatment protocol has been shown to induce behavioral sensitization as well as alterations in dopamine transmission (Kalivas et al., 1993). A lower dose of cocaine was administered for behavioral testing (i.e., days 1 and 7), because this dose is approximately the $\mathbf{E D}_{50}$ for cocaine-induced increases in horizontal photocell counts (Kalivas et al., 1988). Thus, this dose permits accurate quantification of either increases or decreases in photocell counts between days 1 and 7 of treatment. The rats were treated at home on days 2-6 to avail the photocell apparatus for other experiments.

Microinjection procedure. On the challenge day, after a $1 \mathrm{hr}$ adaptation to the photocell cell apparatus (Omnitech), the ohturators were removed from the microinjection guide cannulae and replaced by an injection needle (33-gauge stainless steel) that extended $1 \mathrm{~mm}$ below the tip of the guide cannulae into the nucleus accumbens. Bilateral infusions were made over $60 \mathrm{sec}$ in a volume of $0.3 \mu \mathrm{l} / \mathrm{side}$ (experiment 1 ) or $0.5 \mu \mathrm{l} / \mathrm{side}$ (experiment 4). Twenty seconds later, the injector was removed and the rat was returned to the photocell cage. Behavior was monitored for 120 min after injection.

Microdialysis and measurement of extracellular glutamate and dopamine. The dialysis probes were constructed as described by Robinson and Wishaw (1988), with $\sim 2.0 \mathrm{~mm}$ of active dialysis membrane exposed at the tip. The evening before the experiment, the probes were inserted through the guide cannulae into the nucleus accumbens, and the rats were placed in photocell chambers (Omnitech) permitting simultaneous quantification of behavior. The next day, dialysis buffer containing (in mM) KCl 5 , $\mathrm{NaCl} 120, \mathrm{CaCl}_{2} 1.2, \mathrm{MgCl}_{2} 1.2$, glucose 5, plus PBS 0.2 to give a $\mathrm{pH}$ value of 7.4 and a final sodium concentration of $120.7 \mathrm{~mm}$ was advanced through the probe at a ratc of $1.9 \mu \mathrm{l} / \mathrm{min}$ via a syringe pump (Harvard Instruments, Boston, MA). Two hours after starting perfusion, baseline samples of $20 \mathrm{~min}$ each were collected for $100 \mathrm{~min}$ before beginning drug treatment.

For the measurement of extracellular dopamine, samples were collected into microfuge tubes containing $20 \mu \mathrm{l}$ of mobile phase $[0.1 \mathrm{M}$ citric acid, $75 \mathrm{mM} \mathrm{Na}_{2} \mathrm{HPO}_{4}, 1.5 \mathrm{~mm}$ heptane sulfonic acid, $0.1 \mathrm{~mm}$ EDTA, 15\% methanol $(\mathrm{v} / \mathrm{v}), \mathrm{pH} 4.2]$ plus $100 \mathrm{nmol}$ of dihydroxybenzylamine as the internal standard. After collection, all samples were frozen at $-80^{\circ} \mathrm{C}$ until analyzed. The samples were thawed subsequently and placed in an autosampler (Gilson Medical supplies, Middleton, WI) connected to an HPLC system with electrochemical detection. The dopamine was separated using a $25 \mathrm{~cm} \mathrm{C}-18$ reversed-phase column (Bioanalytical Systems, West LaFayette, IN) and oxidized/reduced using coulometric detection (ESA, Bedford, MA). Threc clectrodes were used: a preinjection port guard cell $(+0.4 \mathrm{~V})$ to oxidize the mobile phase, an oxidation analytical electrode $(+0.3 \mathrm{~V})$, and a reduction analytical electrode $(-0.14 \mathrm{~V})$. Peaks were recorded on a chart recorder and compared with an external standard curve $(10-1000 \mathrm{fmol})$.

For the measurement of extracellular glutamate, samples were collected into $10 \mu \mathrm{I}$ of mobile phase [0.1 $\mathrm{M} \mathrm{Na}_{2} \mathrm{HPO}_{4}, 0.13 \mathrm{~mm} \mathrm{Na}{ }_{2}$ EDTA, $25 \%$ methanol $(\mathrm{v} / \mathrm{v}), \mathrm{pH} 6.4]$ plus $2.0 \mathrm{pmol}$ of homoserine as an internal standard. Precolumn derivatization with $o$-pthaldehyde was performed by an autosampler, and the chromatography was conducted as described above for dopamine, except that a $10 \mathrm{~cm}$ column was used and the electrode currents were set as follows: preinjection port guard cell, +0.7 $\mathrm{V}$; reduction analytical electrode, $-0.25 \mathrm{~V}$; oxidation analytical electrode, $+0.65 \mathrm{~V}$.

Experiment 1: response to AMPA. Twenty days after discontinuing daily saline or cocaine, rats were microinjected with saline into the shell or core of the nucleus accumbens. On days 21 and 22 , after $1 \mathrm{hr}$ of habituation to the behavioral chamber, rats were given two doses of AMPA ( 0.03 or 0.1 $\mu \mathrm{g}$ ) in random order, and motor activity was monitored for $2 \mathrm{hr}$. Thus, the rats were given a total of three microinjections, each separated by a $24 \mathrm{hr}$ intertrial interval.

Experiment 2: dopamine dialysis. On days 21 or 22 after discontinuing repeated cocaine or saline injection, $100 \mathrm{~min}$ of baseline data were collected in either the shell or core followed by the addition of four concentrations of AMPA $(0.1,1.0,10.0$, and $100.0 \mu \mathrm{M})$ to the dialysis buffer. AMPA doses were administered sequentially in ascending order through the probe in the core for $100 \mathrm{~min}$ at each concentration. During both baseline and AMPA administration, samples were taken every $20 \mathrm{~min}$.

Experiment 3: glutamate dialysis. On day 21, after discontinuing repeated cocaine or saline, microdialysis was conducted in the shell or core to measure the levels of extracellular glutamate. After collecting $100 \mathrm{~min}$ of baseline data, rats were challenged with saline $(1.0 \mathrm{ml} / \mathrm{kg}$, i.p. $)$ followed $80 \mathrm{~min}$ later by cocaine $(15 \mathrm{mg} / \mathrm{kg}$, i.p.). Samples were collected for 180 min after cocaine administration before terminating the experiment.

Experiment 4: CNQX pretreatment. Fourteen to twenty-three days after discontinuing daily treatment with cocaine, rats were adapted to the photocell apparatus for $60 \mathrm{~min}$ and then microinjected with CNQX $(0.01$; 0.1 , or $1.0 \mathrm{nmol}$; Tocus Neuramin, Essex, UK) or vehicle [0.1, 1.0, or $10.0 \%$ dimethylsulfoxide (DMSO) in saline] into the core. Five minutes later, rats received an injection of cocaine $(15 \mathrm{mg} / \mathrm{kg}$, i.p.) and were returned to the photocell apparatus where motor activity was monitored for $120 \mathrm{~min}$. At a minimum of 3 d intervals, each rat received a maximum of four combinations of CNQX or DMSO and cocaine. A control experiment was conducted in which animals that did not receive daily cocaine pretreatment were challenged in random order with one of three treatments: (1) CNQX (0.1 nmol) in the core plus systemic saline; (2) DMSO $(1 \% \mathrm{v} / \mathrm{v})$ vehicle in the core plus systemic saline; or (3) either CNQX plus cocaine $(15 \mathrm{mg} / \mathrm{kg}$, i.p.) or DMSO vehicle plus cocaine. The latter cocaine treatments were administered to separate groups of animals to avoid possible confounds of sensitization to a single injection of cocaine (Weiss et al., 1989).

Histology. After the dialysis and behavioral experiments, the rats were given an overdose of pentobarbital (>100 mg/kg, i.p.) and perfused intracardially with PBS followed by $10 \%$ formalin. The brain was removed and stored in $10 \%$ formalin for at least 1 week. The brains then were blocked, and coronal sections $(100 \mu \mathrm{m})$ were taken at the level of the nucleus accumbens with a vibratome. The sections were mounted on gelatin-coated slides and stained with cresyl violet. Probe and cannula placements were determined according to the atlas of Paxinos and Watson (1986) by an individual blind to the rat's behavioral or neurochemical response.

Data analysis. Separate two-way ANOVAs were performed on the totals (horizontal and vertical counts summed across $120 \mathrm{~min}$ ) of the behavioral data. In time-course analyses of behavioral data, a two-way ANOVA with repeated measures over time was conducted. The content of glutamate was expressed both as raw data and as percent change from baseline and evaluated statistically using a two-way ANOVA with repeated measures over time. Based on the average of the last two dialysis samples at each AMPA concentration, extracellular dopamine levels were compared using a two-way ANOVA with repeated measures over dose. Pairwise comparisons were made via a least significant difference or a Scheffe's test (Milliken and Johnson, 1984).

\section{RESULTS}

\section{Sensitization to repeated cocaine}

Shortly after the studies were begun, it became clear that within each experiment a portion of rats receiving daily cocaine did not 


\begin{tabular}{|c|c|c|c|c|}
\hline & $\mathrm{N}$ & Day $1^{\mathrm{a}}$ & Day 7 & Statistics ${ }^{b}$ \\
\hline \multicolumn{5}{|c|}{ Experiment 1: AMPA behavior } \\
\hline Total $^{c}$ & 29 & $16752(1733)^{d}$ & $22156(2362)$ & $t_{(28)}=2.43, p=0.022$ \\
\hline \multicolumn{5}{|l|}{ Core } \\
\hline Sensitized & 10 & $12577(1956)$ & $26633(2696)$ & $\mathbf{t}_{(9)}=4.95, p<0.001$ \\
\hline Nonsensitized & 6 & $18648(4566)$ & $11920(5555)$ & $\mathrm{t}_{(5)}=2.27, p=0.073$ \\
\hline \multicolumn{5}{|l|}{ Shell } \\
\hline Sensitized & 7 & $15088(3784)$ & $27194(4566)$ & $\mathrm{t}_{(6)}=4.51, p=0.004$ \\
\hline Nonsensitized & 6 & $23789(3437)$ & $19050(5395)$ & $\mathrm{t}_{(5)}=2.06, p=0.094$ \\
\hline \multicolumn{5}{|c|}{ Experiment 2: Dopamine dialysis } \\
\hline Total & 20 & $16154(1915)$ & $22864(2168)$ & $\mathrm{t}_{(19)}=2.32, p=0.026$ \\
\hline \multicolumn{5}{|l|}{ Core } \\
\hline Sensitized & 5 & $9839(1934)$ & $17864(2751)$ & $\mathrm{t}_{(4)}=2.34, p=0.044$ \\
\hline Nonsensitized & 4 & $19057(2823)$ & $16306(2384)$ & $\mathrm{t}_{(3)}=0.55, p=0.485$ \\
\hline \multicolumn{5}{|l|}{ Shell } \\
\hline Sensitized & 8 & $17545(3578)$ & $30003(3575)$ & $\mathrm{t}_{(7)}=2.46, p=0.027$ \\
\hline Nonsensitized & 3 & $19096(6211)$ & $20902(4747)$ & $\mathrm{t}_{(2)}-0.23, p=0.829$ \\
\hline \multicolumn{5}{|c|}{ Experiment 3: Glutamate dialysis } \\
\hline Total & 21 & $22074(3093)$ & $25828(3034)$ & $\mathrm{t}_{(20)}=0.88, p=0.387$ \\
\hline \multicolumn{5}{|l|}{ Core } \\
\hline Sensitized & 6 & $12795(2419)$ & $33118(3607)$ & $t_{(5)}=10.97, p<0.001$ \\
\hline Nonsensitized & 6 & $32778(6350)$ & $19553(6108)$ & $t_{(5)}=2.69, p=0.043$ \\
\hline \multicolumn{5}{|l|}{ Shell } \\
\hline Sensitized & 5 & $19199(2683)$ & $32077(3449)$ & $\mathrm{t}_{(4)}=3.66, p=0.022$ \\
\hline Nonsensitized & 4 & $29531(6317)$ & $16493(9222)$ & $\mathrm{t}_{(3)}=1.79, p=0.171$ \\
\hline \multicolumn{5}{|c|}{ Experiment 4: CNQX bchavior } \\
\hline Total & 26 & $20650(2494)$ & $30685(2839)$ & $\mathrm{t}_{(25)}=3.19, p=0.004$ \\
\hline Sensitized & 16 & $16211(2666)$ & $36027(3199)$ & $\mathrm{t}_{(15)}=7.69, p<0.001$ \\
\hline Nonsensitized & 10 & $27751(4105)$ & $22136(4215)$ & $\mathrm{t}_{(9)}=1.84, p=0.099$ \\
\hline
\end{tabular}

${ }^{a}$ Cocaine was administered daily for 1 week. Day 1 corresponds to the first, and day 7 to the last, injection of cocaine.

${ }^{b}$ A two-tailed paired Student's $t$-test was employed to compare day 1 with day 7 in each group. Df is shown in parenthesis.

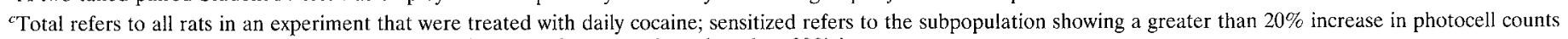
between day 1 and day \%; nonsensitized corresponds to rats demonstrating a less than $20 \%$ increase.

${ }^{d}$ Data are presented as the mean (SEM) horizontal photocell counts over the first 120 min after cocaine injection.

develop behavioral sensitization as defined by an increase in horizontal photocell counts on day 7 compared with day 1 of daily injection. As detailed below, the subpopulation of rats that demonstrated an increase in photocell counts on day 7 versus day 1 showed different alterations in EAA transmission than rats that did not demonstrate an increase in horizontal photocell counts. By setting a criterion of a $20 \%$ increase in horizontal photocell counts on day 7 compared with day 1 , the rats receiving daily cocaine were divided into sensitized ( $>20 \%$ increase) and nonsensitized $(<20 \%$ increase) experimental groups. Using this criterion, between 50 and $75 \%$ of all rats in each experiment were placed in the sensitized group. Table 1 shows the effect of cocaine on horizontal photocell counts on day 1 and day 7 of the daily pretreatment regime. Photocell counts for cocaine-pretreated rats are shown for each experiment as the value for all animals (Total) and after the animals had been divided into sensitized and nonsensitized groups. Table 1 reveals distinguishing characteristics of the sensitized and nonsensitized rats. The rats in the sensitized group demonstrated robust sensitization, with a mean increase in photocell counts ranging from 67.1 to $158.8 \%$ on day 7 compared with day 1 , depending on the experiment. Rats in the nonsensitized group demonstrated no significant difference in photocell counts on day 7 versus day 1 ; however, the counts on day 7 tended to be lower. Rats in the sensitized group tended to have lower photocell counts after the first injection of cocaine compared with the nonsensitized animals. Finally, rats treated with daily saline did not show significant differences in photocell counts between day 1 and day 7 (data not shown).

\section{Experiment 1: microinjection of AMPA}

Figure 1 shows the behavioral response to AMPA microinjection into the core of the nucleus accumbens. AMPA produced a dose-related increase in both horizontal and vertical photocell counts in all three treatment groups. After the highest dose of AMPA $(0.1 \mu \mathrm{g})$, the increase in both horizontal and vertical counts was greater in the sensitized than in the nonsensitized or saline rats. Figure 1 shows the time course for horizontal photocell counts after microinjection of $0.1 \mu \mathrm{g}$ of AMPA into the core. A significant difference between treatment groups was measured that was reflected in the larger behavioral response to AMPA in the sensitized rats, compared with saline-pretreated and nonsensitized animals, between 45 and 90 min after microinjection into the core. At no time point did the behavioral response of the nonsensitized animals differ from controls.

Figure 1 also shows the behavioral response to AMPA microinjection into the shell. Consistent with findings in a previous report (Johnson et al., 1995), AMPA was not as effective at inducing motor activity in the shell compared with the core. 


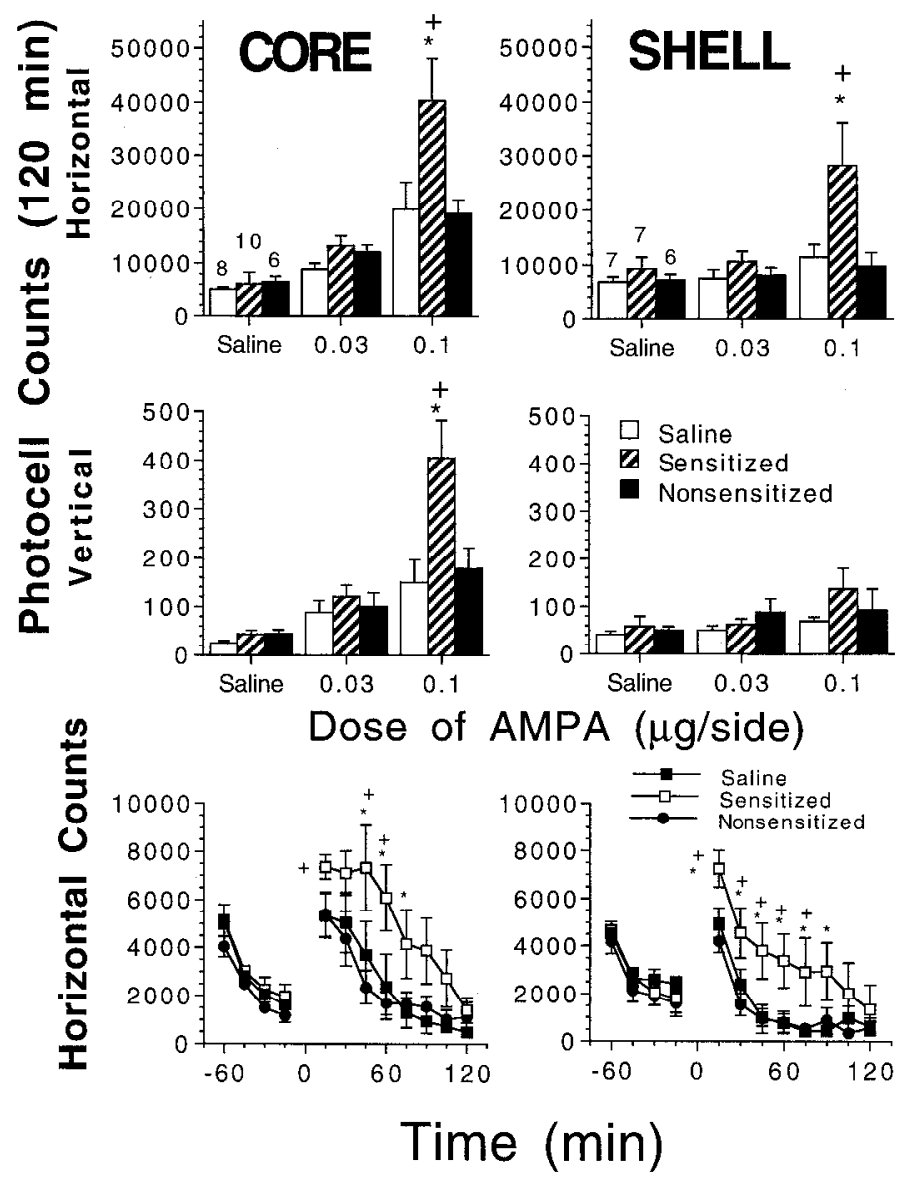

Figure 1. Behavioral effect of AMPA microinjection into the core and shell of the nucleus accumbens of saline (open bars), sensitized (hatched bars), and nonsensitized (filled bars) rats. All animals that displayed a $>20 \%$ increase in behavior between day 7 and day 1 of repeated cocaine administrations were classified as sensitized; all others were defined operationally as nonsensitized. The data are represented as mean $\pm \mathrm{SE}$ horizontal and vertical photocell counts. The number of rats in each group is indicated in the top panel. Top panel, Total horizontal photocell counts (120 min after microinjection). The data were evaluated with a two-way ANOVA (saline/sensitized/nonsensitized $\times$ AMPA dose) with repeated measures over dose. CORE: treatment, $F_{(2,2)}=4.31, p=0.027$; dose, $F_{(2,42)}=24.77, p<0.001$; interaction, $F_{(4,42)}=2.54, p<0.051$. SHELL: treatment, $F_{(2,17)}=6.34, p=0.009$; dose, $F_{(2.34)}=6.79, p=0.003$; interaction, $F_{(4,34)}=2.31, p=0.077$. Middle panel, Total vertical photocell counts (120 min after microinjection). The data were evaluated with a two-way $\Lambda N O V \Lambda$ (saline/sensitized/nonsensitized $\times$ AMPA dose) with repeated measures over dose. CORE: treatment, $F_{(2.21)}=5.06, p=0.016$; dose, $F_{(2,42)}=22.48, p<0.001$; interaction, $F_{(4,42)}=2.75, p<0.041$. SHELL: treatment, $F_{(2,17)}=1.34, p=0.288$; dose, $F_{(2,34)}=3.49, p=$ 0.042 ; interaction, $F_{(4,34)}=0.69, p=0.602$. Bottom panel, Time course of the horizontal photocell counts shown in the top panel corresponding to $0.1 \mu \mathrm{g}$ of AMPA. Time: -60 to $-15 \mathrm{~min}$ corresponds to the $60 \mathrm{~min}$ adaptation before administering AMPA at time 0 . The data were evaluated using a two-way ANOVA (saline/sensitized/nonsensitized $\times$ time) with repeated measures over time. CORE: treatment, $F_{(2,21)}=5.46, p=$ 0.013 ; time, $F_{(11.231)}=14.57, p<0.001$; interaction, $F_{(22.231)}=1.03, p=$ 0.475. SHELL: treatment, $F_{(2,17)}=3.19, p=0.067$; time, $F_{(11,187)}=22.16$, $p<0.001$; interaction, $F_{(22,187)}=2.12, p=0.004 .{ }^{*} p<0.05$ comparing treatments to saline using a least significant difference test (Milliken and Johnson, 1984); ${ }^{+} p<0.05$ comparing sensitized to nonsensitized.

Although the ANOVA did not reveal a significant interaction between dose and treatment group in either horizontal or vertical photocell counts, there was a significant effect of dose in both behavioral parameters and a significant effect of treatment group in horizontal photocell counts. As with the core, the difference

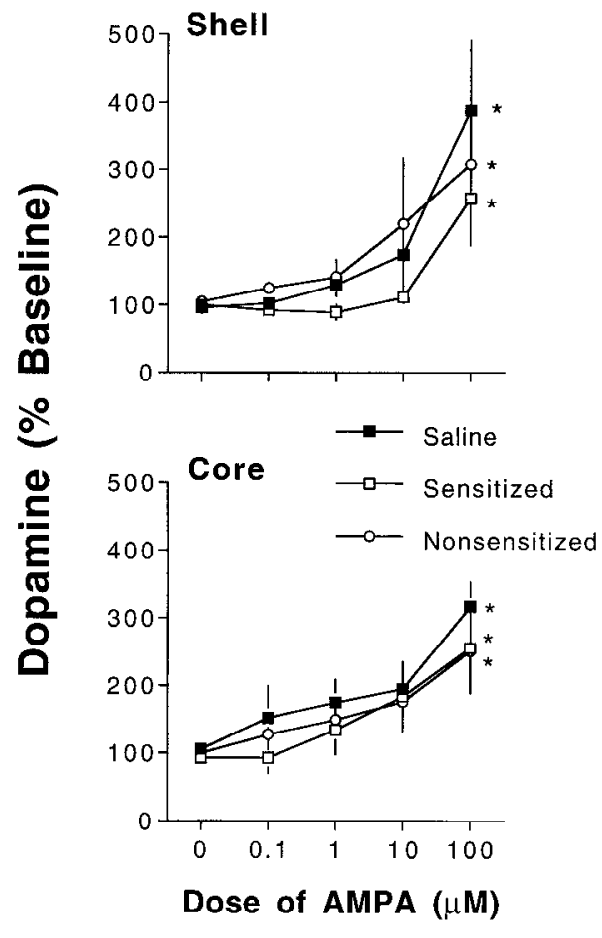

Figure 2. Effect of AMPA administration through the dialysis probe in the core and shell on extracellular dopamine content. The experiment was conducted at 21 or $22 \mathrm{~d}$ after discontinuing repeated cocaine or saline. The data were normalized to percent change from baseline, and the last two samples taken at baseline and at each AMPA concentration were averaged. The top panel shows data obtained from the Shell, and the bottom panel shows data obtained from the Core. The data were analyzed using a two-way ANOVA (saline/sensitized/nonsensitized $\times$ dose) with repeated measures over dose. Core: treatment, $F_{(2,11)}=0.41, p=0.671$; time, $F_{(4,44)}$ $=15.65, p<0.001 ;$ interaction, $F_{(8,44)}=0.24, p=0.982$. Shell: treatment, $F_{(2,15)}=0.17, p=0.843$; time, $F_{(4,60)}=5.53, p<0.001$; interaction, $F_{(8,60)}$ $=0.58, p=0.793 .{ }^{*} p<0.05$ comparing each group to its own basal value with a least significant difference test (Milliken and Johnson, 1984).

between treatment groups in horizontal counts was attributable primarily to the increased response to $0.1 \mu \mathrm{g}$ of AMPA microinjected into the shell of the sensitized compared with nonsensitized or saline rats. Figure 1 shows the time course of the effect of AMPA $(0.1 \mu \mathrm{g})$ microinjection into shell on horizontal photocell counts. The behavioral response to AMPA was significantly greater in sensitized rats, compared with saline-pretreated and nonsensitized animals, for the first $90 \mathrm{~min}$ after microinjection. At no time point did the behavioral response of the nonsensitized animals differ from that of controls.

\section{Experiment 2: AMPA-induced dopamine release}

The perfusion of AMPA through a microdialysis probe in the core or shell produced a dose-dependent increase in extracellular dopamine in the nucleus accumbens (Fig. 2). There were no significant differences in the dopamine response between the sensitized, nonsensitized, and saline groups. The baseline values for dopamine did not differ significantly among the three treatment groups in either the core $\left(F_{(2,15)}=0.12, p=0.892\right.$; saline, 0.136 $\pm 0.054 \mathrm{pmol} / \mathrm{sample}$; sensitized, $0.124 \pm 0.062 \mathrm{pmol} / \mathrm{sample}$ nonsensitized, $0.094 \pm 0.047 \mathrm{pmol} / \mathrm{sample})$ or the shell $\left(F_{(2,16)}=\right.$ $0.59, p=0.567$; saline, $0.019 \pm 0.004 \mathrm{pmol} / \mathrm{sample}$; sensitized, $0.023 \pm 0.003 \mathrm{pmol} / \mathrm{sample}$; nonsensitized, $0.027 \pm 0.010$ $\mathrm{pmol} / \mathrm{sample}$ ). 


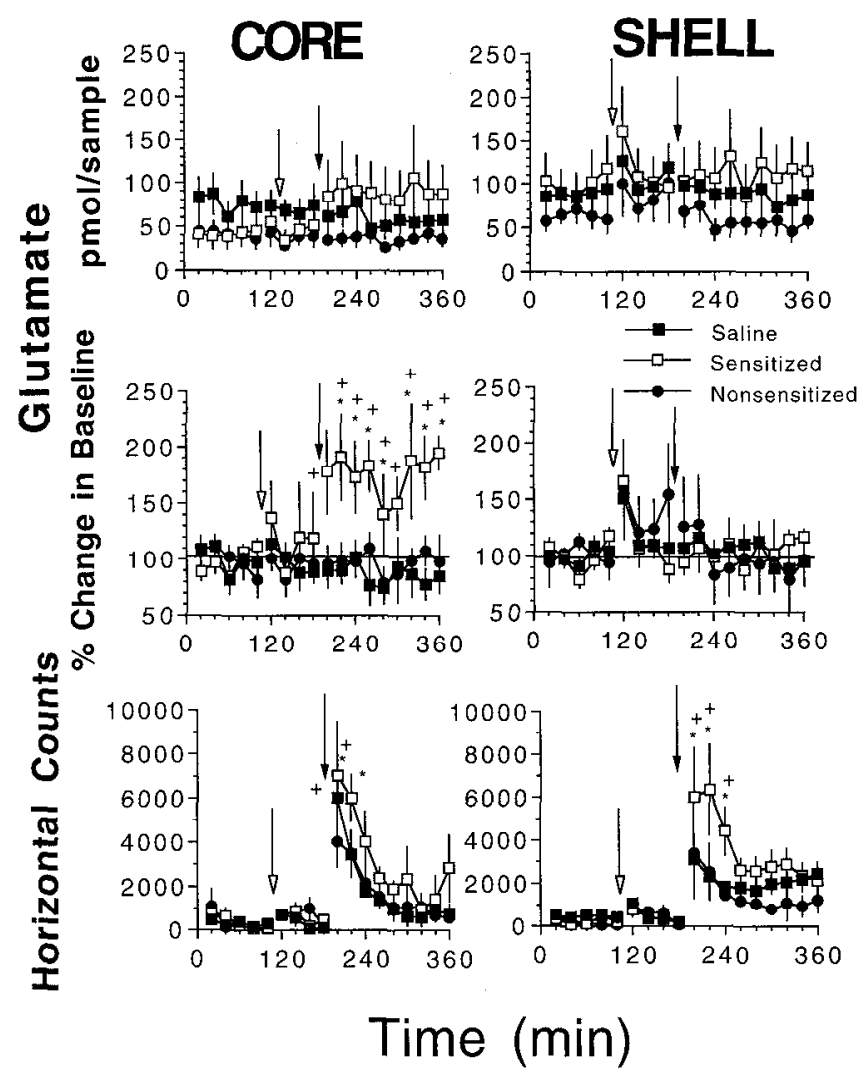

Figure 3. Effect of saline and cocaine $(15 \mathrm{mg} / \mathrm{kg}$, i.p.) on extracellular glutamate in the core and shell of saline-pretreated and cocainepretreated rats at $21 \mathrm{~d}$ of withdrawal. The data are presented as mean \pm SEM. The top panel shows the level of extracellular glutamate (pmol/ sample), and the middle panel shows percent change from basal levels of glutamate. The bottom panel shows the motor response obtained simultaneously with the neurochemistry. In each panel, the data were evaluated using a two-way ANOVA (saline/scnsitized/nonsensitized $\times$ time) with repeated measures over time. The open arrow indicates the administration of saline (after $100 \mathrm{~min}$ ), and the closed arrow indicates the injection of cocaine (after $180 \mathrm{~min}$ ). Top panel, CORE: treatment, $F_{(2,15)}=0.77, p=$ 0.482 ; time, $F_{(17,255)}=0.96, p=0.501$; interaction, $F_{(34,255)}=2.21, p<$ 0.001. SHELL: treatment, $F_{(2,15)}=0.72, p=0.504 ;$ time, $F_{(17,255)}=2.49$, $p<0.001$; interaction, $F_{(34,255)}=0.68, p=0.913$. Middle panel, CORE: treatment, $F_{(2,15)}=7.44, p=0.006$; time, $F_{(17,255)}=1.37, p=0.153$; interaction, $F_{(34,255)}=1.91, p=0.003$. SHELL: treatment, $F_{(2,15)}=0.02$, $p=0.981$; time, $F_{(17.255)}=2.71, p<0.001$; interaction, $F_{(34.255)}=0.75, p$ $=0.846$. Bottom panel, CORE: treatment, $F_{(2,15)}=4.56, p=0.028$; time, $F_{(17,255)}=14.22, p<0.001$; interaction, $F_{(34,255)}=0.90, p=0.632$. SHELL: treatment, $F_{(2,15)}=3.82, p=0.046$; time, $F_{(17,255)}=11.74, p<$ 0.001 ; interaction, $F_{(34,255)}=1.47, p=0.051{ }^{*} p<0.05$ comparing scnsitized with saline at a given timc using a least significant difference test (Milliken and Johnson, 1984); ${ }^{+} p<0.05$ comparing sensitized with nonsensitized.

\section{Experiment 3: extracellular glutamate after a cocaine challenge}

Figure 3 shows the effect of a saline and cocaine injection on extracellular levels of glutamate in the core of the nucleus accumbens. Injection of saline did not alter extracellular glutamate levels in the core in any treatment group. There was a significant difference between treatment groups in response to a subsequent injection of cocaine $(15 \mathrm{mg} / \mathrm{kg}$, i.p.). Cocaine administration clcvated the levels of extracellular glutamate significantly in the sensitized group compared with both the nonsensitized and saline-pretreated rats. Significant elevations occurred immediately after administering cocaine (200 min) and continued until

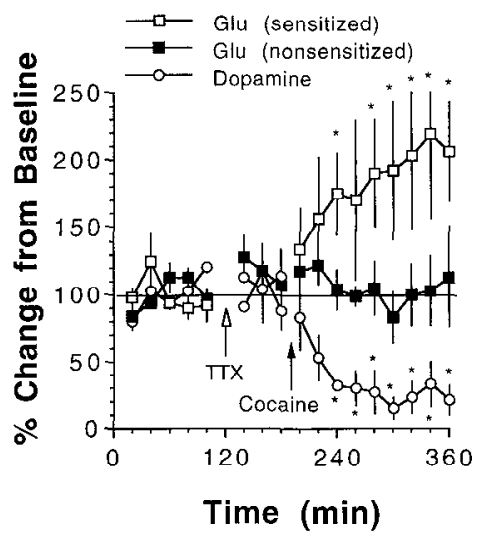

Figure 4. Effect of TTX $(1.0 \mu \mathrm{M})$ on extracellular levels of glutamate and dopamine in the core of the nucleus accumbens of rats pretreated $21 \mathrm{~d}$ earlier with daily cocaine. TTX was introduced into the dialysis buffer at the open arrow $(120 \mathrm{~min})$, and Cocaine $(15 \mathrm{mg} / \mathrm{kg}$, i.p.) was administered at the closed arrow (after $180 \mathrm{~min}$ ). The dopamine values were obtained from samples of three animals (2 sensitized, 1 nonsensitized) used to measure glutamate. The data are shown as mean \pm SEM percent change in baseline and were analyzed using a one-way repeated-measures ANOVA. Glu (sensitized): baseline $=81 \pm 25 \mathrm{pmol} / \mathrm{sample}, n=3, F_{(16.50)}$ $=3.13, p=0.003$. Glu (nonsensitized): baseline $=81 \pm 20 \mathrm{pmol} / \mathrm{sample}$, $n=3, F_{(16,50)}=0.76, p=0.715$. Dopamine: baselinc $=135 \pm 20$ fmol/sample, $n=3, F_{(16,50)}=10.07, p<0.001 .{ }^{*} p<0.05$ compared with baseline using Scheffe's test for multiple comparisons.

the end of the experiment. The average basal levels of glutamate in both groups of cocaine-pretreated animals tended to be lower than in saline-pretreated rats $\left(F_{(2,15)}=1.68, p=0.080\right.$; saline, 77 $\pm 19 \mathrm{pmol} / \mathrm{sample}$; sensitized, $42 \pm 15 \mathrm{pmol} / \mathrm{sample}$; nonsensitized, $41 \pm 13 \mathrm{pmol} / \mathrm{sample})$. Figure 4 also shows the behavioral response to saline and cocaine administration in the three treatment groups. Although there were significant main effects of time and treatment, there was not a significant interaction. However, if the sums of the photocell counts obtained after the injection of cocaine were compared with a one-way ANOVA, the sensitized group demonstrated more photocell counts in response to the cocaine challenge than did either the nonsensitized or the saline group $\left(F_{(2,15)}=5.46, p=0.017\right.$; saline $(n=6), 16,552 \pm 3321$; sensitized $(n=6), 28,460 \pm 3289$; nonsensitized $(n=6), 14,090 \pm$ $3260)$.

Figure 3 also illustrates that there were no significant differences in extracellular glutamate levels in the shell of the nucleus accumbens among the sensitized, nonsensitized, and saline treatment groups after an injection of saline or cocaine. Likewise, there were no differences in the basal levels among the three groups $\left(F_{(2,15)}=0.57, p=0.567\right.$; saline, $89 \pm 15 \mathrm{pmol} / \mathrm{sample}$; sensitized, $80 \pm 18 \mathrm{pmol} / \mathrm{sample}$; nonsensitized, $63 \pm 10 \mathrm{pmol} /$ sample). In contrast to the extracellular glutamate levels, analysis of the corresponding behavioral data revealed significant treatment and time effects, with a near-significant interaction. If the sums of the horizontal photocell counts obtained after the injection of cocaine were compared with a one-way ANOVA, the sensitized group demonstrated more photocell counts in response to the cocaine challenge than did either the nonsensitized or the saline group $\left(F_{(2,15)}=5.49, p=0.016\right.$; saline $(n=9), 19,497 \pm$ 2525 ; sensitized $(n=5), 32,175 \pm 4850$; nonsensitized $(n=4)$, $13,820 \pm 3207)$.

To determine whether the extracellular glutamate was derived from cytosolic or vesicular pools, tetrodotoxin (TTX; $1.0 \mu \mathrm{M}$ ) was included in the dialysis buffer. Figure 4 demonstrates that with the 

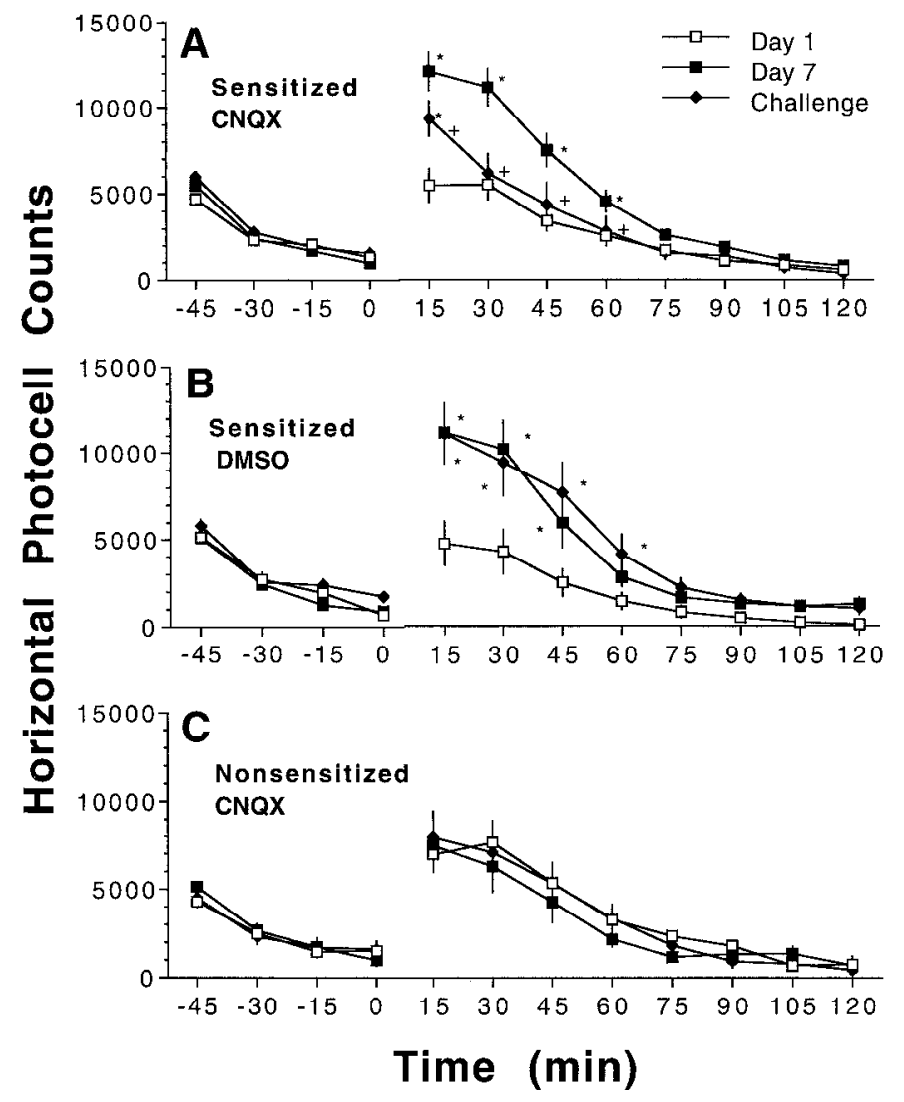

Figure 5. Time course of the effects of CNQX (0.1 nmol) or DMSO vehicle $(1 \% \mathrm{v} / \mathrm{v})$ microinjection into the core of the nucleus accumbens on the behavioral effect of cocaine given $2-3$ weeks after discontinuing daily cocaine. Time: -45 to $0 \mathrm{~min}$ corresponds to the adaptation period before cocaine $(15 \mathrm{mg} / \mathrm{kg}$, i.p.) and CNQX administration, and 15-120 min reflects the behavioral response to these drugs. Also shown are the responses to daily cocaine on day 1 (open squares) and day 7 (filled squares). The data are presented as mean \pm SEM horizontal photocell counts and were evaluated using a two-way ANOVA with repeated measures over time. $A$, Sensitized animals were injected with CNQX and cocaine: day, $F_{(2,34)}=7.33, p<0.003$; time, $F_{(11,374)}=88.82, p<0.001$; interaction, $F_{(22,374)}=6.27, p<0.001 . B$, Sensitized animals were injected with DMSO and cocaine: day, $F_{(2,21)}=5.29, p<0.02$; time, $F_{(11,231)}=$ $48.34, p<0.014$; interaction, $F_{(22,231)}=3.51, p<0.001$. $C$, Nonsensitized animals were injected with CNQX and cocaine: day, $F_{(2,20)}=0.13, p>$ 0.05 ; time, $F_{(21,220)}=45.01, p<0.001$; interaction, $F_{(22,220)}-0.54, p>$ $0.05 .{ }^{*} p<0.05$ comparing treatments to day 1 using a least significant difference test (Milliken and Johnson, 1984); ${ }^{+} p<0.05$ comparing day 7 to CNQX or DMSO.

exception of the first time bin, the increase in extracellular glutamate observed in the core after a cocaine challenge in the sensitized group of rats was not inhibited by 'I"I'X. Likewise, the level of glutamate in the nonsensitized rats was not altered. However, as noted in previous reports (Westerink et al., 1987), the concentration of extracellular dopamine in the same samples was reduced significantly below basal levels by TTX.

\section{Experiment 4: effect of CNQX on the expression of sensitization}

Figure 5 shows that CNQX $(0.1 \mathrm{nmol})$ pretreatment in the core of the nucleus accumbens reduced the motor stimulant effect of cocaine in sensitized rats. Pretreatment with CNQX ( $0.1 \mathrm{nmol})$ before a cocaine challenge at 14-23 d after the last repeated cocaine injection reduced the augmented level of motor activity. From 15 to $60 \mathrm{~min}$ after injection, the motor response was
Table 2. Effect of CNQX pretreatment $(0.1$ nmol) into the core on the behavioral response to a cocaine challenge $(15 \mathrm{mg} / \mathrm{kg}$, i.p. $)$ in control rats

\begin{tabular}{lcc} 
Treatment $^{a}$ & $\begin{array}{l}\text { DMSO/cocaine } \\
(n=15)\end{array}$ & $\begin{array}{l}\text { CNQX/cocaine } \\
(n=8)\end{array}$ \\
\hline DMSO/Saline & $7809(997)^{b}$ & $7232(1754)$ \\
CNQX/Saline & $9266(1186)$ & $7107(1508)$ \\
DMSO or CNQX plus cocaine & $18405(3322)^{c}$ & $19709(3292)$
\end{tabular}

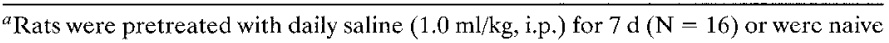
$(\mathrm{N}=7)$. Beginning at 2 weeks after the last daily injection, rats were divided into two groups, DMSO/Cocaine and CNOX/Cocaine. Each group of rats were given all three treatments in random order separated by a $72 \mathrm{hr}$ intertrial interval. DMSO $(1 \% \mathrm{v} / \mathrm{v})$ or CNQX was microinjected into the core $5 \mathrm{~min}$ before systemic saline or cocaine ( 15 $\mathrm{mg} / \mathrm{kg}$, i.p.). Two treatments were identical in each group (DMSO/saline and CNOX/ saline) and for the other treatment, one group received DMSO/cocaine and the other received CNOX/cocaine. The data were not significantly different between the rats pretreated with daily saline and the naive animals. These data were pooled in Table 2 for statistical analysis.

${ }^{b}$ The data are shown as mean (SEM) horizontal photocell counts for 120 min after administering systemic cocaine or saline. The data were evaluated with a two-way ANOVA with repeated measures over treatment. Group $F_{(1,21)}=0.06, p=0.816$; treatment $\mathrm{F}_{(2,42)}=15.87, p<0.001$; interaction $\mathrm{F}_{(2,42)}=0.28, p=0.760$.

${ }^{c} p<0.05$, compared with $\mathrm{DMSO} /$ saline and CNQX/saline. No other comparisons were statistically significant.

reduced by CNQX compared with the response produced by cocaine on day 7 and was equivalent to the motor response produced on day 1 at all time points except the first time bin. When sensitized rats were pretreated with DMSO vehicle $(1 \%$ $\mathrm{v} / \mathrm{v}$ ) in the core before a cocaine challenge, the motor response was equivalent to the augmented levels on day 7 and significantly elevated over the day 1 cocaine response. Figure 5 also shows the response to CNQX in nonsensitized rats. Consistent with behavior defined as nonsensitized, the response to cocaine on day 7 was not greater than on day 1. Further, pretreatment with CNQX did not alter the response to a cocaine challenge compared with the response on either day 1 or day 7. Table 2 shows that this dose of CNQX did not alter the response to an acute systemic cocaine challenge in rats that did not receive daily pretreatment with cocaine. Likewise, CNQX did not alter the response to a systemic saline injection.

Two other doses of CNQX were examined (data not shown). Whereas pretreatment of sensitized rats with $0.01 \mathrm{nmol}$ of CNQX was ineffective, $1.0 \mathrm{nmol}$ of CNQX reduced the number of photocell counts on the cocaine challenge day compared with day 7 of repeated cocaine pretreatment. In nonsensitized animals, there was not a significant alteration in either day 1 or day 7 cocaineinduced activity by any dose of CNQX. Concentrations of the DMSO vehicle used to solubilize the corresponding doses of CNQX did not alter motor activity in sensitized rats.

\section{Histology}

Figure 6 depicts the location of the ventral tip of the microinjection cannulae in the nucleus accumbens for the behavioral experiments. The cannulae were distributed between the core and the medial shell regions of the nucleus accumbens. All cannulae used in experiment 4 were in the core, whereas placements from experiment 1 were in either the shell or the core. The micrograph shows histology from an animal used in experiment 1 that was microinjected with the highest dose of AMPA $(0.1 \mu \mathrm{g})$ and illustrates the lack of neurotoxicity beyond the mechanical destruction associated with the injection procedure. Figure 7 depicts the dialysis probe placements in the nucleus accumbens. In experiments 2 and 3, the probes were located in both the shell and 

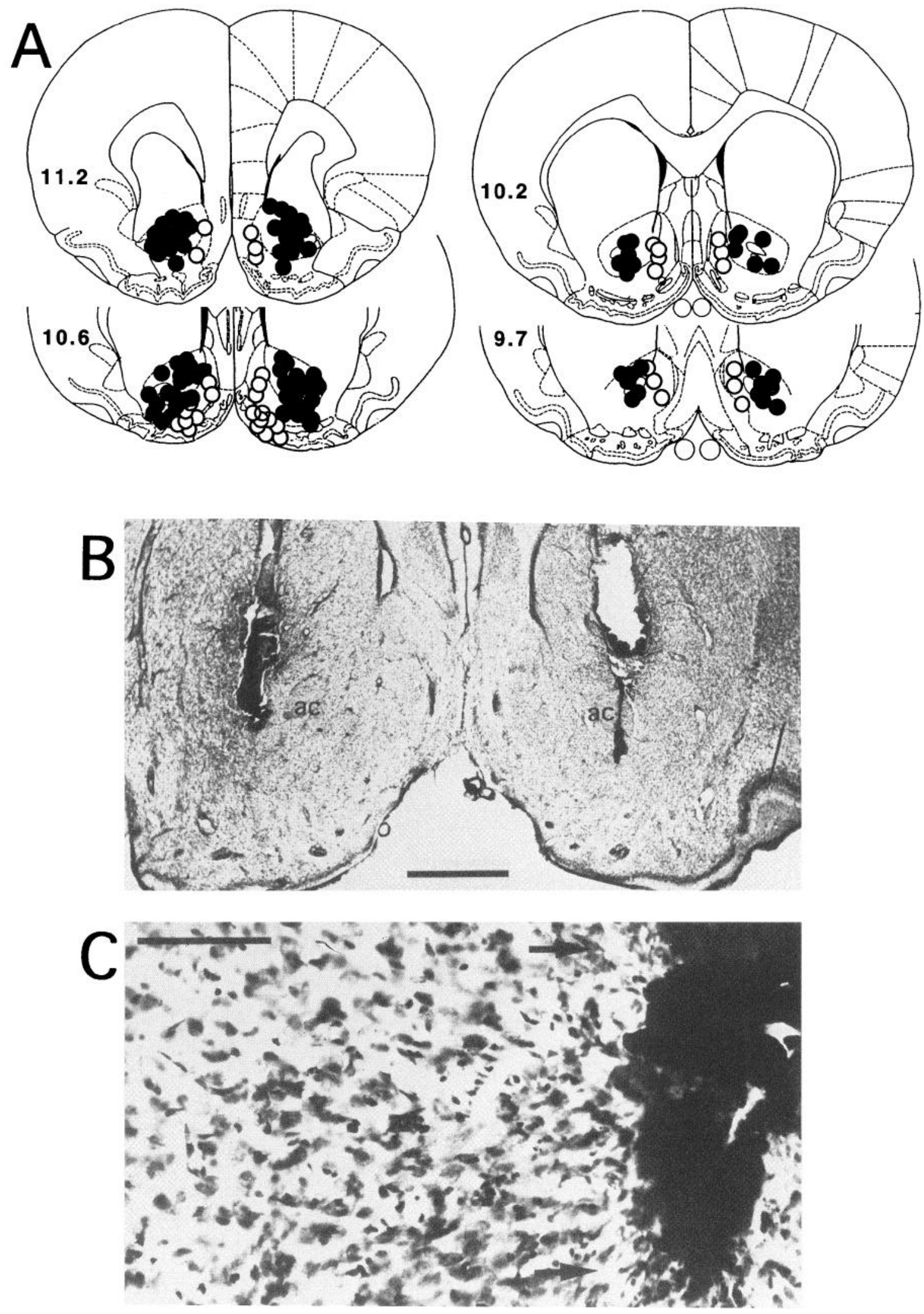

Figure 6. Location of the microinjection cannula tips in the nucleus accumbens from experiments 1 and $4(A)$. The numbers indicate millimeters rostral to the interaural line according to the atlas of Paxinos and Watson (1986). The open circles represent cannula placements in the shell, and the filled circles represent cannula placements in the core. The micrographs $(B$ and $C)$ are representative of an animal microinjected with AMPA in experiment 2. Note the lack of neurotoxicity outside the mechanical damage produced by penetration of the injection cannulae. Scale bars: $B, 2 \mathrm{~mm} ; C, 0.2 \mathrm{~mm}$. 

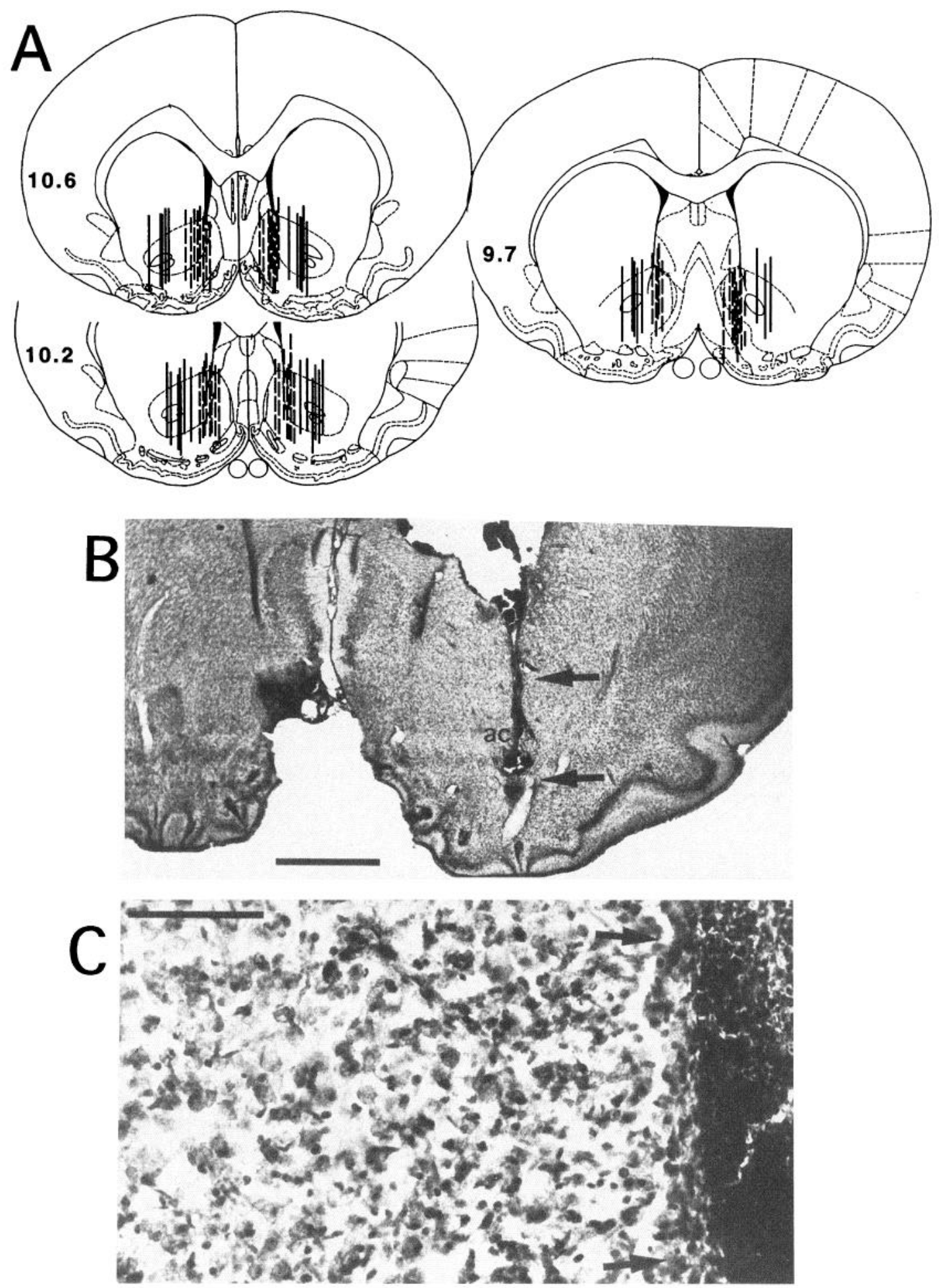

Figure 7. Location of dialysis probe placements in the nucleus accumbens from experiments 2 and $3(A)$. The numbers indicate millimeters rostral to the interaural line according to the atlas of Paxinos and Watson (1986). The solid lines represent probe placements in the core, and the dashed lines depict placements in the shell. The micrographs $(B$ and $C)$ are from an animal used in experiment 2 and show the lack of neurotoxicity outside of the mechanical damage produced by the probe after perfusion of AMPA through the dialysis probe. The arrows approximate the dorsal and ventral extent of the active portion of the dialysis membrane. Scale bars: $B, 2 \mathrm{~mm} ; C, 0.2 \mathrm{~mm}$.

core. Note that some dialysis probes placed in the core had active membrane dorsal to the core in the ventral striatum or ventral to the core in the lateral limb of the shell. Also, some probe placements in the shell penetrated the medial edge of the core or the diagonal band of Broca. The micrograph was from an animal used in experiment 2 in which $100 \mu \mathrm{M}$ AMPA was passed through the dialysis probe. Note the lack of neurotoxicity outside the mechanical destruction produced by the dialysis probe and guide cannula. 


\section{DISCUSSION}

These experiments demonstrate that augmented EAA transmission in the nucleus accumbens is associated with the expression of behavioral sensitization in rats pretreated with daily cocaine injections. Augmented EAA transmission was observed only in rats developing behavioral sensitization to repeated cocaine pretreatment (sensitized) and was not present in rats pretreated with cocaine that did not develop behavioral sensitization to criterion (nonsensitized) or in control animals. Three aspects of EAA transmission were augmented: (1) The behavioral response to microinjection of the non-NMDA agonist AMPA into either the shell or core of the nucleus accumbens was increased in rats sensitized to cocaine versus nonsensitized or saline-pretreated rats. (2) A cocaine challenge elevated extracellular glutamate levels in the core, but not the shell, only in rats sensitized to cocaine. (3) The sensitized motor response to cocaine was prevented by pretreatment of the core with the AMPA antagonist CNQX.

\section{Neurotransmission in the nucleus accumbens in the expression of behavioral sensitization to cocaine}

The nucleus accumbens is thought to mediate the transfer of information from the limbic system to motor systems, and both EAA and dopamine transmission are considered to be important modulators in this process (Mogenson et al., 1993; LeMoal and Simon, 1991; Kalivas et al., 1993). It has been proposed that the expression of behavioral sensitization to psychostimulants is associated with alterations in EAA and dopamine transmission within the nucleus accumbens (Kalivas and Stewart, 1991; Nestler, 1992; White et al., 1995b). Supporting this proposition, the present data demonstrate that there are changes in presynaptic and postsynaptic EAA transmission in the nucleus accumbens. Because the behavioral effects of $\Lambda \mathrm{MP} \Lambda$ and $\mathrm{CNQX}$, and the elevation in extracellular glutamatc, are present only in the subgroup of rats that develop behavioral sensitization to repeated cocaine administration, the changes in EAA transmission in the nucleus accumbens may be critical determinants in the expression of behavioral sensitization.

The absence of changes in nonsensitized rats indicates that repeated cocaine administration is not a sufficient condition for producing augmented EAA transmission. Another important condition permitting effects on EAA transmission may be genetic variation in responsiveness to cocaine (Nestler et al., 1993; Hooks and Kalivas, 1994). Also, differential development of conditioning to environmental stimuli may be involved. There is substantial evidence for a conditioned component of psychostimulantinduced behavioral sensitization (Tilson and Rech, 1973; Post and Weiss, 1988; Stewart and Vezina, 1988; Pert et al., 1992). Supporting a possible role for EAA transmission in the nucleus accumbens in psychostimulant-conditioned behaviors, the nuclei supplying EAA afferents to the nucleus accumbens, including the prefrontal cortex, hippocampus, and amygdala (Kelley and Domesick, 1982; Kelley et al., 1982; Berendse and Groenewegen, 1990; Berendse et al., 1992; Zahm and Brog, 1992), contribute to both the development of conditioned behaviors (Mishkin and Appenzeller, 1987; Goldman-Rakic, 1988; Dudai, 1989) and the behavioral sensitization to psychostimulants (Yoshikawa et al., 1991; Pert et al., 1992; Dahlin et al., 1994).

Figure 4 reveals a dissociation in the time course of the increase in extracellular glutamate in the core and the behavioral response to a cocaine challenge. This indicates that augmented extracellular glutamate is not the sole determinant of the sensitized behavioral response. The involvement of multiple transmitters in me- diating a change in complex motor behaviors is not surprising. Although experiment 2 demonstrated that the augmented behavioral responsiveness to AMPA was independent of AMPAinduced release of dopamine, this monoamine has been linked consistently to the expression of behavioral sensitization to psychostimulants (Robinson and Becker, 1986; Kalivas and Stewart, 1991; Nestler, 1992; White et al., 1995b). In addition to glutamate and dopamine, serotonin, dynorphin, and enkephalin have been identified in recent studies as possibly playing a role in the expression of behavioral sensitization to cocaine (Cunningham et al., 1992; Heidbreder et al., 1993a,b; Parsons and Justice, 1993; Sala et al., 1995). None of the investigations supporting a role for dopamine or the other neurotransmitters divided rats treated with repeated cocaine into sensitized and nonsensitized groups. Thus, it is not known whether the alterations in these neurotransmitters, as in glutamate, are associated only with animals that develop behavioral sensitization.

\section{Mechanisms underlying augmented extracellular glutamate in the core}

With the exception of during the first $20 \mathrm{~min}$ after injecting cocaine, the increase in extracellular glutamate was not affected by blocking voltage-dependent sodium channels with TTX. This indicates that the increase in extracellular glutamate was not attributable to impulse-dependent depolarization (Westerink et al., 1987) and argues that the elevation in extracellular glutamate produced by a cocaine challenge in cocaine-sensitized rats is attributable either to a decrease in glutamate uptake by neurons and glia or to impulse-independent, nonvesicular glutamate release. The former seems unlikely, because a reduction in uptake would be expected to elevate basal levels of extracellular glutamate, and the basal concentration of glutamate was somewhat rcduccd in the core of cocaine-pretreated rats (see Fig. 4). On the other hand, impulse-independent release of glutamate via reversal of the uptake transporter is well documented in pathophysiolngical situations, such as brain ischemia (Choi, 1988; Attwell et al., 1993; Nicholls, 1993). The fact that the cocaine-induced increase in the extracellular concentration of glutamate in the core of sensitized rats continued for the duration of the experiment may indicate that cocaine is triggering pathophysiological release of cytoplasmic glutamate. However, consistent with the lack of overt neurotoxicity in the nucleus accumbens of cocaine-treated animals (Kleven et al., 1988; Yeh and De Souza, 1991), the increased levels of glutamate produced by cocaine were at least 10 -fold lower than the extracellular levels achieved after brain ischemia (Nilsson et al., 1990; Simpson et al., 1992). Ischemia-induced carrier-mediated efflux of glutamate is attributable to decreased $\mathrm{Na}^{+} / \mathrm{K}^{+}$-ATPase activity, which degrades the electrochemical gradient maintaining the inward directional bias for glutamate transport (Attwell et al., 1993; Nicholls, 1993). Three studies support a direct or indirect interaction between cocaine and $\mathrm{Na}^{+} / \mathrm{K}^{+}$. ATPase. (1) Cocaine inhibits neuronal $\mathrm{Na}^{+} / \mathrm{K}^{+}$-ATPase in fetal neurons (Lien et al., 1994). (2) Dopamine inhibits $\mathrm{Na}^{+} / \mathrm{K}^{+}$. ATPase in striatal cells (Bertorello et al., 1990), and the augmentation in extracellular dopamine (Pettit et al., 1990; Kalivas and Duffy, 1993; Parsons and Justice, 1993; Hooks et al., 1994) and postsynaptic dopamine responsiveness (Henry and White, 1991; Terwilliger et al., 1991) after repeated cocaine administration may inhibit $\mathrm{Na}^{+} / \mathrm{K}^{+}$-ATPase sufficiently to promote carrier-mediated efflux of glutamate. (3) Repeated treatment with another psychostimulant, methamphetamine, reduces ATP levels in the striatum (Chan et al., 1994). 


\section{Mechanisms underlying augmented AMPA receptor responsiveness}

One explanation for the augmented behavioral response to AMPA in rats sensitized to repeated cocaine is the regulation of non-NMDA ionotropic receptors by dopamine receptor stimulation. Electrophysiological studies show that dopamine modulates the excitatory effects of amygdala and hippocampal stimulation on accumbal neurons (for review, see Mogenson et al., 1993) and that EAAergic afferents from the hippocampus, amygdala, and prefrontal cortex form synaptic contacts on the same accumbal cells as dopaminergic axon terminals (Sesack and Pickel, 1990, 1992; Meredith et al., 1993). Also, $D_{1}$-receptor stimulation enhances glutamate-induced membrane polarizations in retinal bipolar cells (Maguire and Werblin, 1994). The marked increase in the inhibitory effects of $D_{1}$-receptor agonists in the nucleus accumbens of rats pretreated with daily cocaine or amphetamine (Henry et al., 1989; Iigashi et al., 1989; Wolf et al., 1993) supports the possibility that $\mathrm{D}_{1}$-receptor stimulation may influence AMPA receptormediated neurotransmission.

Although the present results show that AMPA-induced behavioral hyperactivity is increased in cocaine-sensitized animals, White et al. (1995a) demonstrated recently that the stimulation of accumbal neurons by iontophoretically applied glutamate is blunted after repeated cocaine. It is not precisely clear how EAA afferents to the nucleus accumbens influence neuronal activity to modulate motor behaviors. This lack of clarity is reflected by two paradoxes (for review, see Kalivas et al., 1993; Mogenson et al., 1993). (1) Microinjection of dopamine or EAA agonists into the nucleus accumbens elicits motor activity, yet dopamine antagonizes the electrophysiological response to the stimulation of EAA afferents. (2) Despite the fact that activation of all EAA afferents stimulates neuronal activity in the nucleus accumbens, stimulation of EAA afferents from the hippocampus produces motor activity and stimulation of EAA afferents from the amygdala causes freezing behavior. These discrepancies indicate that responses produced by AMPA administration to single neurons may not reflect the behavioral response elicited when many neurons are affected by microinjected AMPA. Another possible explanation rests on the fact that the electrophysiological data were obtained from anesthetized animals (White et al., 1995a). Considering the distinction in AMPA responsiveness between sensitized and nonsensitized rats in the present report, electrophysiological measurements made in conscious rats may reflect more adequately the behavioral output of the nucleus accumbens (Henriksen and Giachino, 1993).

\section{CONCLUSIONS}

These studies reveal that augmented EAA transmission in the nucleus accumbens may have a role in the expression of behavioral sensitization to cocaine. This possibility is buttressed by the fact that the increases in extracellular glutamate and behavioral responsiveness to AMPA receptor stimulation occurred only in rats pretreated with daily cocaine that developed behavioral sensitization. Although changes in many transmitters in the nucleus accumbens are likely to be involved, the present data suggest that glutamate transmission acts as one of the primary determinants in the expression of the bchavioral sensitization to cocaine.

\section{REFERENCES}

Angrist BM, Gershon S (1970) The phenomenology of experimentally induced amphetamine psychosis: preliminary observations. Biol Psychiatry 2:95-107.

Attwell D, Barbour B, Szatkowski M (1993) Nonvesicular release of neurotransmitter. Neuron 11:401- 407.
Berendse HW, Groenewegen HJ (1990) Organization of the thalamostriatal projections in the rat, with special emphasis on the ventral striatum. J Comp Neurol 299:187-228.

Berendse HK, Galis DE, Graaf Y, Groenewegen HJ (1992) Topographical organization and relationship with ventral striatal compartments of prefrontal corticostriatal projections in the rat. J Comp Neurol 316:314-367.

Bertorello AM, Hopfield JF, Aperia A, Greengard P (1990) Inhibition by dopamine of $\left(\mathrm{Na}^{+}+\mathrm{K}^{+}\right)$ATPase activity in neostriatal neurons through $\mathrm{D}_{1}$ and $\mathrm{D}_{2}$ dopamine receptor synergism. Nature 347:386-388.

Chan P, Di Monte DA, Luo J-J, DeLanney LE, Irwin I, Langston JW (1994) Rapid ATP loss caused by methamphetamine in the mouse striatum: relationship between energy impairment and dopaminergic neurotoxicity. J Neurochem 62:2484-2487.

Choi DW (1988) Glutamate neurotoxicity and diseases of the nervous systems. Neuron 1:623-634.

Clarke PBS, Jakubovic A, Fibiger HC (1988) Anatomical analysis of the involvement of mesolimbocortical dopamine in the locomotor stimulant actions of D-amphetamine and apomorphine. Psychopharmacology 96:511-520.

Cunningham KA, Paris JM, Goeders NE (1992) Serotonin neurotransmission in cocaine sensitization. Ann NY Acad Sci 654:117-127.

Dahlin SL, Hu XT, Xue C-J, Wolf ME (1994) Lesions of the prefrontal cortex or amygdala, but not fimbria fornix, prevent sensitization of amphetamine-stimulated horizontal activity. Soc Neurosci Abstr 20:1621.

Deutch $\Lambda$ Y, Cameron DS (1992) Pharmacological characterization of dopamine systems in the nucleus accumbens core and shell. Neuroscience 46:49-57.

Dudai Y (1989) The neurobiology of memory. Oxford: Oxford UP.

Goldman-Rakic PS (1988) Topography of cognition: parallel distributed networks in primate association cortex. Annu Rev Neurosci 11:137-156.

Goldstein M, Deutch AY (1992) Dopaminergic mechanisms in the pathogenesis of schizophrenia. FASEB J 6:2413-2421.

Heidbreder C, Goldberg SR, Shippenberg TS (1993a) Inhibition of cocaine-induced sensitization by the $\delta$-opioid receptor antagonist naltrindole. Eur J Pharmacol 243:123-127.

Heidbreder C, Goldberg SR, Shippenberg TS (1993b) The kappa-opioid receptor agonist U-69593 attenuates cocaine-induced behavioral sensitization in the rat. Brain Res 616:335-338.

Henriksen SJ, Giachino J (1993) Functional characteristics of nucleus accumbens neurons: evidence obtained from in vivo electrophysiological recordings. In: Limbic motor circuits and neuropsychiatry (Kalivas PW, Barnes CD, eds) pp 101-124. Boca Raton, FL: CRC.

Henry DJ, White FJ (1991) Repeated cocaine administration causes persistent enhancement of $D_{1}$ dopamine receptor sensitivity within the rat nucleus accumbens. J Pharmacol Exp Ther 258:882-890.

Henry DJ, Greene MA, White FJ (1989) Electrophysiological effects of cocaine in the mesnaccumbens dopamine system: repeated administration. J Pharmacol Exp Ther 251:833-839.

Higashi H, Inanaga K, Nishi S, Uchimura N (1989) Enhancement of dopamine actions on rat nucleus accumbens neurones in vitro after methamphetamine pretreatment. J Physiol (Lond) 408:587-603.

Hooks MS, Kalivas PW (1994) Modeling individual susceptibility to substance abuse. In: Strategies for studying brain disorders. (Palomo T, ed). Madrid: Farrand.

Hooks MS, Duffy P, Striplin C, Kalivas PW (1994) Behavioral and neurochemical sensitization following cocaine self-administration. Psychopharmacology 115:265-272.

Johnson KJJ, Churchill L, Klitenick MA, Hooks MS, Kalivas PW (1996) Involvement of the ventral tegmental area in locomotion elicited from the nucleus accumbens or ventral pallidum. $\mathbf{J}$ Pharmacol Exp Ther, in press.

Kalivas PW, Duffy P (1993) Time course of extracellular dopamine and behavioral sensitization to cocaine. I. Dopamine axon terminals. J Neurosci 13:266-275.

Kalivas PW, Duffy P (1995) Selective activation of dopamine transmission in the shell of the nucleus accumbens by stress. Brain Res 675:325-328.

Kalivas PW, Stewart J (1991) Dopamine transmission in the initiation and expression of drug- and stress-induced sensitization of motor activity. Brain Res Rev 16:223-244.

Kalivas PW, DuMars LA, Skinner C (1988) Behavioral and neurochemical effects of acute and daily cocaine administration in rats. J Pharmacol Exp Ther 245:485-492.

Kalivas PW, Churchill L, Klitenick MA (1993) The circuitry mediating the translation of motivational stimuli into adaptive motor responses. 
In: Limbic motor circuits and neuropsychiatry (Kalivas PW, Barnes CD, eds), pp 237-287. Boca Raton, FL: CRC.

Karler R, Calder LD, Turkanis SA (1991) DNQX blockade of amphetamine behavioral sensitization. Brain Res 552:295-300.

Karler R, Calder LD, Bedingfield JB (1994) Cocaine behavioral sensitization and the excitatory amino acids. Psychopharmacology 115:305-310.

Kelley AE, Domesick VB (1982) The distribution of the projection from the hippocampal formation to the nucleus accumbens in the rat: an anterograde and retrograde horseradish peroxidase study. Neuroscience 7:2321-2335.

Kelley AE, Domesick VB, Nauta WJH (1982) The amygdalostriatal projection in the rat: an anatomical study by anterograde and retrograde tracing methods. Neuroscience 7:615-630.

Kelly PH, Iversen SD (1975) Selective 6-OHDA-induced destruction of mesolimbic dopamine neurons: abolition of psychostimulant-induced locomotor activity in rats. Eur J Pharmacol 40:45-56.

Kleven MS, Woolverton WL, Seiden LS (1988) Lack of long-term monoamine depletions following repeated or continuous exposure to cocaine. Brain Res Bull 21:233-237.

Koob GF, Robledo P, Mardou A, Caine SB (1993) The mesocorticolimbic circuit in drug dependence and reward: a role for the extended amygdala? In: Limbic motor circuits and neuropsychiatry (Kalivas PW, Barnes CD, eds), pp 289-310. Boca Raton, FL: CRC.

Le Moal M, Simon H (1991) Mesocorticolimbic dopaminergic network: functional and regulator roles. Physiol Rev 71:155-234.

Lien R, Mishra OM, Graham E, Delivoria-Papadopoulos M, Andlay EK (1994) Alteration of brain cell membrane function following cocaine exposure in fetal guinea pig. Brain Res 637:249-254.

Maguire G, Werblin F (1994) Dopamine enhances a glutamate-gated ionic current in OFF bipolar cells of the tiger salamander retina. $J$ Neurosci 14:6094-6101.

Maldonado-Irizarry CS, Kelley $\Lambda$ E (1994) Differential behavioral effects following microinjection of an NMDA antagonist into nucleus accumbens subregions. Psychopharmacology 116:65-72.

Meredith GE, Pennartz CMA, Groenewegen HJ (1993) The cellular framework for chemical signalling in the nucleus accumbens. Prog Brain Res 99:3-24.

Milliken GA, Johnson DE (1984) Analysis of messy data, Vol I, Designed experiments. Belmont, CA: Lifetime Learning.

Mishkin M, Appenzeller T (1987) The anatomy of memory. Sci Am $256: 62-71$.

Mogenson GJ, Brudzynski SM, Wu M, Yang CR, Yim CCY (1993) From motivation to action: a review of dopaminergic regulation of limbicnucleus accumbens-pedunculopontine nucleus circuitries involved in limbic-motor integration. In: Limbic motor circuits and neuropsychiatry (Kalivas PW, Barnes CD, eds), pp 193-236. Boca Raton, FL: CRC.

Nestler EJ (1992) Molecular mechanisms of drug addiction. J Neurosci $12: 2439-2450$.

Nesiler EJ, Hope BT, Widnell KL (1993) Drug addiction: a model for the molecular basis of neural plasticity. Neuron 11:995-1006.

Nicholls DG (1993) The glutaminergic nerve terminal. Eur J Biochem 212:613-631.

Nilsson P, Hillered L, Ponten U, Ungerstedt U (1990) Changes in cortical extracellular levels of energy-related metabolites and amino acids following concussive brain injury in rats. J Cereb Blood Flow Metab 10:631-637.

Parsons LH, Justice Jr JB (1993) Serotonin and dopamine sensitization in the nucleus accumbens, ventral tegmental area and dorsal raphe nucleus following repeated cocaine administration. J Neurochem 61:1611-1619.

Paxinos G, Watson C (1986) The rat brain in stercotaxic coordinates. New York: Academic.

Pellegrino LK, Pellegrino AS, Cushman AJ (1979) A stereotaxic atlas of the rat brain. New York: Plenum.

Pert A, Post R, Weiss SRB (1992) Conditioning as a critical determinant of sensitization induced by psychomotor stimulants. In: Neurobiology of drug abuse: learning and memory (Erinoff L, ed), pp 208-241. Washington, DC: NIDA.

Pettit HO, Pan H-T, Parsons LH, Justice Jr JB (1990) Extracellular concentrations of cocaine and dopamine are enhanced during chronic cocaine administration. J Neurochem 55:798-804.

Pierce RC, Kalivas PW (1995) Amphetamine produces sensitized increases in locomotion and extracellular dopamine preferentially in the nucleus accumbens shell of rats administered repeated cocaine. J Pharmacol Exp Ther 275:1019-1029.

Post RM, Weiss SRB (1988) Sensitization and kindling: implications for the evolution of psychiatric symptomatology. In: Sensitization in the nervous system (Kalivas PW, Barnes CD, eds), pp 257-292. Caldwell, NJ: Telford.

Pulvirenti L, Berrier R, Kreifeldt M, Koob GF (1994) Modulation of loconotor activity by NMDA receptors in the nucleus accumbens core and shell regions of the rat. Brain Res 664:231-236.

Robinson TE, Becker JB (1986) Enduring changes in brain and behavior produced by chronic amphetamine administration: a review and evaluation of animal models of amphetamine psychosis. Brain Res Brain Res Rev 11:157-198.

Robinson TE, Wishaw IQ (1988) Normalization of extracellular dopamine in the striatum following recovery from a partial unilateral 6-OHDA lesion of the substantia nigra: a microdialysis study in freely moving rats. Brain Res 450:209-224.

Sala M, Braida D, Colombo M, Groppetti A, Sacco S, Gori E, Parenti M (1995) Behavioral and biochemical evidence of opioidergic involve ment in cocaine sensitization. J Pharmacol Exp Ther 274:450-457.

Sato M (1992) A lasting vulnerability to psychosis in patients with previous methamphetamine psychosis. Ann NY Acad Sci 654:160-170.

Segal DS, Schuckit MA (1983) Animal models of stimulant-induced psychosis. In: Stimulants: neurochemical, behavioral, and clinical perspectives (Creese I, ed), pp 131-167. New York: Raven.

Sesack SR, Pickel VM (1990) In the medial nucleus accumbens, hippocampal and catecholaminergic terminals converge on spiny neurons and are in apposition to each other. Brain Res 527:266-272.

Sesack SR, Pickel VM (1992) Prefrontal cortical efferents in the rat synapse on unlabeled neuronal targets of catecholamine terminal in the nucleus accumbens septi and on dopamine neurons in the ventral tegmental area. J Comp Neurol 320:145-160.

Simpson RE, O'Regan MH, Perkins LM, Phillis JW (1992) Excitatory transmitter amino acid release from the ischemic rat cerebral cortex: effects of adenosine receptor agonists and antagonists. J Neurochem $58: 1683-1690$.

Stewart J, Vezina P (1988) Conditioning and behavioral sensitization. In: Sensitization in the nervous system (Kalivas PW, Barnes CD, eds), pp 207-224. Caldwell, NJ: Telford.

Terwilliger R, Beitner-Johnson D, Svarino KA, Crain SM, Nestler EJ (1991) A general role for adaptations in G-proteins and cyclic AMP system in mediating the chronic actions of morphine and cocaine on neuronal function. Brain Res 548:100-110.

Tilson HA, Rech RH (1973) Conditioned drug effects and absence of tolerance to $d$-amphetamine induced motor activity. Pharmacol Biochem Behav 1:149-153.

Weiss SRB, Post RM, Pert A, Woodward R, Murman D (1989) Contextdependent cocaine sensitization: differential effect of haloperidol on development versus expression. Pharmacol Biochem Behav 34:655-661.

Westerink BHC, Tuntler J, Damsma G, Rollema H, de Vries JB (1987) The use of tetrodotoxin for the characterization of drug-enhanced dopamine release in conscious rat studies by brain dialysis. Naunyn Schmiedebergs Arch Pharmacol 336:502-507.

White FJ, Hu X-T, Zhang X-F, Wolf ME (1995a) Repeated administration of cocaine or amphetamine alters neuronal responses to glutamate in the mesoaccumbens dopamine system. J Pharmacol Exp Ther 273:445-454.

White FJ, Xiu Y-H, Henry DJ, Zhang X-F (1995b) Neurophysiological alterations in the mesocorticolimbic dopamine system during repeated cocaine administration. In: The neurobiology of cocaine addiction (Hammer R, ed), pp 99-120. Boca Raton, FL: CRC.

Wolf ME, White FJ, Nassar R, Bróoderson RJ, Khansa MR (1993) Differential development of autoreceptor subsensitivity and enhanced dopamine release during amphetamine sensitization. J Pharmacol Exp Ther 264:249-255.

Yeh SY, De Souza EB (1991) Lack of neurochemical evidence for neurotoxic effects of repeated cocaine administrations in rats on brain monoamine neurons. Drug Alcohol Depend 27:51-61.

Yoshikawa T, Shibuya H, Kaneno S, Toru M (1991) Blockade of behavioral sensitization to methamphetamine by lesion of the hippocampoaccumbal pathway. Life Sci 48:1325-1332.

Zahm DS, Brog JS (1992) On the significance of subterritories in the "accumbens" part of the rat ventral striatum. Neuroscience 50:751-767. 